\begin{tabular}{|l|l|}
\hline Postprint Version & 1.0 \\
\hline Journal website & $\underline{\mathrm{http}: / / \mathrm{dx} . \text { doi.org/10.1016/j.pec.2010.11.003 }}$ \\
\hline Pubmed link & $\underline{\mathrm{http}: / / \text { www.ncbi.nlm.nih.gov/pubmed/21146342 }}$ \\
\hline DOI & $10.1016 / \mathrm{j}$. pec.2010.11.003 \\
\hline
\end{tabular}

This is a NIVEL certified Post Print, more info at http://www.nivel.eu

\title{
Web-enabled video-feedback: A method to reflect on the communication skills of experienced physicians
}

\author{
JANNEKe NOORDMAN *, PETERVERHAaK, SANDRAVANDULMEN
}

Netherlands Institute for Health Services Research (NIVEL), Utrecht, The Netherlands

\begin{abstract}
Objective:To describe our web-enabled video-feedback method designed to reflect on the communication skills of experienced physicians.

Methods: Participating physicians $(n=28)$ received a 'personal web link' to two of their video-recorded consultations. After watching the consultations physicians received feedback by telephone or in a face-to-face meeting, structured around an individualized feedback report. This report contained scores on the communication behavior of the physician in comparison with colleagues and their own communication behavior observed in a previous study, as well as patients' opinions about their physician's communication behavior. The physicians were asked to reflect on their communication skills and to comment on the usefulness and efficiency of the feedback method.

Results: Almost all physicians were satisfied with the feedback method and in particular valued the web-enabled link to the video-recorded consultations and the structured written report. Feedback by telephone or face-to-face feedback was considered equally appropriate.

Conclusion: This web-enabled video-feedback method is a useful and structured design to reflect on the communication skills of physicians.

Practice implications: As part of continuing medical education, feedback on communication skills should become a recurrent activity for experienced physicians. This method can also be used to reflect on the communication skills of medical students.
\end{abstract}

\section{INTRODUCTION}

Continuing medical education (CME) is necessary to update and reflect on the knowledge and (communication) skills of experienced physicians in everyday practice D.A. Davis, M.A. Thomson, A.D. Oxman and R.B. Haynes, Changing physician performance: a systematic review of the effect of continuing medical education strategies, J Amer Med Assoc 274 (1995), pp. 700-705. | [1], [2], [3] and [4]. CME can have various forms, such as didactic large-group presentations, workshops, small groups, individualized feedback, training sessions or integrating several approaches [2].

While communication skills training for medical students has become part of their education since the early nineties in Europe, USA and Australia [5], [6] and [7], post-graduate education focuses mainly on biomedical and technical aspects of health care [5]. This means that most physicians receive no structural 
training or feedback on their communication skills after vocational training. Furthermore, previous research suggests that there is an inverse relationship between years in practice and certain aspects of the quality of such as adherence to standards of practice for diagnosis, screening, appropriate therapy and knowledge [8]. It is possible that over the years physician's communication with the patient also becomes a routine operation, leading to a decrease in patient-centered and empathic behavior and a more businesslike communication pattern [9] and [10].

Several studies found that medical education can result in an overall improvement of the communication skills of medical students and physicians, especially when the training includes a form of feedback on providers' actual performance [6] and [11]. Aspegren [6] for instance described several studies where feedback resulted in receiving more information from the patient, better interpersonal skills and an ability to interview beyond traditional teaching (i.e., instruction, lecture, textbook).

Successful feedback has been found to consist of well observed tasks and competencies, an expert observer and feedback provider, highly specific information, an explicit standard, personal observation, an explicit aim of performance improvement and a plan to re-observe [12]. In addition, the most effective feedback is feedback provided by a credible, authoritative source over a number of years [13].

Video-feedback seems an optimal method to reflect on and teach communication skills to physicians. Such feedback is based on reviews of recorded real-life physician-patient interactions. Video-feedback has been demonstrated to enhance physicians' reflection on their own communication skills and has a more long-term impact than traditional didactic methods [7], [14], [15] and [16]. A more recently developed and time-efficient approach is the online demonstration of video-recorded communication skills [17].

Although Cegala and Lenzmeire Broz identify a general lack of information about which specific communication skills were taught to physicians in previous studies [18], there are studies that indicate which communication aspects are feasible for feedback. Common elements include: patient-centered behavior [7], [11], [19], [20], [21] and [22], shared decision making [11] and [22], summarizing [11], [19], [20] and [22], information giving [7], [19] and [21], non-verbal behavior [19] and [22] and showing and responding to empathy/feelings [7], [19], [20], [21] and [23]. Patients' opinions are also important for providing feedback: physicians are highly motivated to learn from the views of their patients [24] and sensitive to patient dissatisfaction [25].

In this context we designed a video-feedback method, including patients' evaluations, to reflect on the communication skills of experienced physicians. The aim of the present paper is to describe our partly webenabled, video-feedback method which is structured around a written individualized report. We will (1) test the feasibility of our new feedback method and (2) explore opinions of experienced physicians regarding the feedback method.

In line with others our feedback involves 'collecting information on performance measures for individual physicians and then providing this information to the physicians with comparisons with colleagues and other standards' [12] and [26].

\section{METHODS}

\subsection{Population}

Forty Dutch primary care physicians participated in a study on physician-patient communication in 20072008 [27]. These physicians agreed to have approximately twenty consecutive, everyday consultations videotaped. The recording with an unmanned camera took place on one or two random days. This resulted in a total of 808 video-recorded consultations (patient response 78\%). The majority of these physicians $(\mathrm{n}=35)$ had their consultations also video-taped in a previous study in 2001 [28] and [29].

Physicians who participated in the study are all members of the Netherlands Information Network of General Practice (LINH). LINH is a representative network of currently 180 Dutch physicians and 340,000 patients, spread throughout the Netherlands [30]. A convenience sample of 93 physicians was drawn from LINH, with priority for physicians that had participated in the 2001 study. Forty physicians agreed to participate in the feedback study (response 44\%). These doctors are representative for Dutch physicians regarding sex and practice form (solo -, duo-, group practice or health centre).

The study was carried out according to Dutch privacy legislation. The privacy regulation was approved by the Dutch Data Protection Authority. Current practice in the Netherlands does not require ethical approval for this observatory study. However, ethical principles were adhered to in this study, and the anonymity of 
patients and physicians is guaranteed. All participating physicians and patients filled in an informed consent form before the recording of the consultation. Due to the position of the camera patients were only visible at the back of their head or not visible at all. Patients could withdraw their consent at any time; no one did.

\subsection{Web-enabled video-feedback}

Initially, 39 of the 40 physicians were interested in receiving feedback. Five of these only received feedback on medication adherence as part of a parallel project and were therefore not included in the present study. From the remaining 34 videotaped physicians, six physicians withdrew nonetheless from the feedback due to a previously unforeseen busy working period, which resulted in a total of 28 physicians who received web-enabled feedback.

Physicians who agreed to participate in the video-feedback received a secured 'personal web link' on which they could observe the two selected consultations. This enabled them to watch the consultations at their office desk or at home. To this purpose, physicians obtained an email with two personal web links; by clicking on the links they were able to watch two of their own video-recorded consultations. They could watch these consultations through a media player as many times as they liked for about two weeks and had the option to pause the videos. After watching the consultations eight of the physicians received feedback on their communication behavior by telephone for half an hour, the other 20 in a face-to-face one-hour meeting.

The feedback was structured around an individualized feedback report. This report contained items on the communication behavior of the physician in comparison with their colleagues and with their own communication behavior in a previous study in 2001 [28] and [29]. The report contained also patient ratings about the communication of the physician. All topics in the feedback report were systematically discussed (Table 1). The feedback report consisted of 16 figures or tables with short explanations (see for illustration Fig. 1). This meant that during physicians' feedback the following was discussed: the overall ratings of all the physicians, the mean ratings of the consultations of the particular physician (in the recent and previous study), and the two selected consultations of the physician.

\section{[TABLE1]}

At the start of the feedback session, physicians were asked to evaluate their communication behavior (in general and during the selected consultations in particular) (see Table 2). We did not give directions on the topics they should pay attention to when evaluating their own communication. Afterwards they were asked to comment on the usefulness and efficiency of the feedback method (Table 2). During the feedback session the physicians could react at any time to the results that were discussed. For the purpose of analysis, we audio-recorded physicians' reactions during the face-to-face meetings; during the telephone feedback their comments were not recorded but were written down instantly.

\section{[FIGURE 1][TABLE 2]}

In the previous study, carried out in 2001 [28] and [29], physicians also received feedback based on videorecorded consultations. The aim of the previous feedback was also to reflect on the communication skills of experienced physicians. In contrast with the previous feedback, the recent feedback method enabled physicians to watch their consultations through a web-enabled link beforehand. Besides, the recent feedback was structured around a written report.

Nearly all physicians who participated in the recent feedback $(n=20)$ had received feedback in the previous 2001 study; consequently they could reflect on and compare both feedback methods.

After the feedback the personal internet link to the consultations was removed. Physicians who participated in the feedback received CME points (for education purpose).

\subsection{Observations}

The consultations were coded by six observers, using an observation list. Observers in 2008 and 2001 were trained by the same trainer.

Observers rated the amount of instrumental and affective behavior and the amount of patient-directed gaze measured using the Roter Interaction Analysis System (RIAS) [31]. Each utterance (word or sentence) by the physician and patient was coded using a list of 40 behavioral codes. Instrumental communication behavior refers to question-asking, exchanging information and advice and affective behavior includes 
reassurance and showing empathy [31]. Patient-directed gaze, i.e., the time that the physician looked into the patient's face, was measured as a percentage of the time that the physician was in sight.

Besides, the visit length (in minutes) was registered as well as the level of patient-centeredness. Patientcenteredness was measured with three, five-point likert scaled items, looking at the extent to which the physician (1) gives space to the patient and encourages him/her to disclose concerns, (2) finds mutual agreement (for instance, on a treatment plan) and (3) takes patient's perspective into account.

We also observed whether or not life style behaviors (smoking, alcohol, diet and physical activity) were discussed with the patient [32] and [33] and if and what kind of computer use physicians showed during consultations [27]. In addition, we observed if physicians discussed topics relevant in view of the Dutch Medical Treatment Act [28]; i.e., (1) informing the patient about medical research and treatment, (2) discussing treatment options and mention alternatives, (3) mention possible side-effects and risks, (4) making a decision in concordance with the patient and (5) asking permission for research and treatment.

Besides, we mentioned ad hoc other noteworthy positive and negative communication aspects for each physician. For example, one physician summarized his consultations always at the end, another physician had a waiting attitude in many cases. Other noteworthy communication aspects were: exploring clearly, structuring the consultation (logical sequence of phases i.e., history taking, physical examination, advice about treatment), and informing the patient using printed materials or leaflets. All these assessments and comparisons, next to patients' ratings (see Section 2.4), were recorded in the written personalized feedback report.

We compared the mean scores of a physician with those of his or her 39 colleagues and with his or her own mean scores observed in a previous study in 2001.

Lastly, we selected two consultations per physician: one in which they showed a good communication style and one consultation in which there was room for improvement. We selected the two consultations based on the mean scores of the communication style of the physician (about e.g., patient centeredness, decision making, affective and instrumental behavior) relative to their own communication in the other recorded consultation and in relation with the other 39 participating physicians. Our aim was not to provide physicians with the extensive list of above mentioned topics as skills to discuss in every consultation, but to make them aware of their communication style and show them how to use the communication topics in an appropriate way in a particular consultation.

To compute interrater reliability, 70 of the same consultations were rated by four observers. Because the interrater reliability for the RIAS categories [31] was already calculated with Pearson's R [34] in 2001 we decided to calculate the same categories also with Pearson's R for 2008. The interrater reliability for the other observed topics (between two observers) in 2008 were calculated with Cohen's kappa [35]. When an utterance was coded less than $5 \%$ we did not calculate the interrater reliability.

\subsection{Patients' ratings}

Patients filled in a questionnaire immediately before and after the recording of the consultation. They indicated their preferences and experiences regarding decision making about a possible treatment before and after the consultations, on a 5-point scale (1: the physician has to take/took all the decisions, 2: the physician has to take/took the decision, but in concordance with the patient, 3: the physician and patient have to take/took a decision together, 4 : the patient has to take/took the decision, but in concordance with the physician, 5: the patient has to take/took all the decisions).

Furthermore, patients completed the QUOTE (Quality of Care through the Patients' Eyes) communication questionnaire [28] and [29], before and after the recorded consultation. Using this QUOTE-com, patients described their pre-visit preferences and post-visit experiences regarding communication aspects of the physician, on a 4-point scale. For example, before the consultation they indicated their level of importance on 'it is important that the doctor listened to me well' and after the consultation 'the doctor listened to me well' (1: not, 2: not really, 3: yes, 4: yes definitely). In line with a previous study, we assigned these aspects to affect-oriented communication or instrumental-oriented communication [28]. Affect-oriented communication consists for example of attentive and empathic behavior by the physician - listening and showing interest in the patient. Instrumental behavior includes exchanging information and advice, diagnosing and problem solving. 


\section{RESULTS}

\subsection{Interrater reliability}

The interrater reliability is high for almost all observed RIAS behavior, but moderate for the empathy physicians showed towards the patient and structuring of the consultation.

For all the other observed categories Kappa is sufficiently high (Table 3).

\section{[TABLE 3]}

\subsection{Communication assessment}

Physicians commented on their own communication behavior. The following examples illustrate how physicians evaluated their communication with the patient. One physician noticed that: 'I had a better posture than during my vocational training, but I use the computer quite a lot'. Another physician mentioned that: 'I could not quite figure out the treatment demand of the patient and I did not mention alternative treatment options'. He also pointed out that: 'I should think more transcend and from the point of view of the patient and should figure out what the patient wants'. Another physician stated that he has sometimes problems with consultations becoming a routine procedure and that he also should explore the problem from the point of view of the patient more. Furthermore, several physicians mentioned that time pressure resulted in less patient-centered behavior.

Overall, physicians recognized their own behavior and physicians' self reported outcomes were in agreement with observed outcomes.

\subsection{Technological aspects of feedback}

All the physicians were able to watch their consultations through the web-enabled link, only two physicians mentioned a problem with the volume of their videos but this was immediately fixed (the volume button was switched off). Physicians used the web-enabled link on computers with Microsoft Windows as operating system.

\subsection{Physicians' experiences with feedback}

Almost all physicians $(n=27)$ were positive about the feedback method. They valued the fact that they could watch the video-recorded consultations online in their own time and that the feedback was structured around a written report.

One physician mentioned that he liked in particular the structured written report and patients' opinions about his communication. Another physician was very pleased with the feedback: 'That I could watch my consultations online is fantastic! I think that every physician should do this, preferably every year. I also think that the feedback was nicely structured'. One of his colleagues also liked to see her video-recorded consultations and referred to it as a sort of benchmark for communication. Two more physicians indicated that the written report was very nice and one of them mentioned that he received a lot more information about his communication than expected. An other physician was also content with the feedback method, but preferred guidance in what communication aspects he should pay attention to before he was asked to evaluate his consultations.

Furthermore, half of the physicians who received feedback by telephone $(n=4)$ referred to the method as time saving. Besides, physicians who received feedback by telephone and physicians who received face-toface feedback evaluated the feedback as equally satisfactory. Although, one physician who received telephone feedback preferred face-to-face feedback. He suggested using a video-conference method or webcam instead.

We also asked whether physicians preferred this feedback method or the feedback they received in the previous study in 2001. Five physicians who participated in the previous study did not remember the specifics of the feedback they received in 2001 and could not compare the feedback methods. The other physicians $(n=15)$ found the present feedback method more efficient, time saving and more complete than the previous one. As stated before, they particularly liked the web-enabled link to the video-recorded consultations and the written report. One physician mentioned that 'this form of feedback is a better way to reflect on communication'. Another stated that this feedback method was more useful because: 'I could always look back into the written report and remember where to pay attention to'. 
Lastly, comments from physicians show that the two selected consultations were well chosen. Physicians recognized themselves and mentioned that the two consultations were opposites; indicating that one showed more positive and the other more negative elements of their communication.

\section{DISCUSSION AND CONCLUSION}

\subsection{Discussion}

This article described the feasibility and evaluation of a distinct video-feedback method designed to reflect on the communication skills of experienced physicians.

The initial reactions from physicians suggest that our method is feasible and appreciated and that the format was appropriate. Physicians liked in particular the web-enabled link to the video-recorded consultations and the structured written report. Comments about the content of our feedback consisted of one physician who mentioned that he received more information about his communication than expected and several physicians who stated that they in particular liked patients' opinions about their communication.

Physicians also indicated that the method was time saving, because they could watch the consultations online in their own time. Besides, feedback by telephone was considered time efficient. Especially, when one has to travel a long distance feedback by telephone would be an appropriate option. On the other hand video-recording, observing all consultations and writing a personal report is time consuming for the researchers. A possible solution is to observe fewer consultations than recorded and ask physicians directly after recording which consultation(s) they report as 'good' or 'need improvement' regarding their communication with the patient. In practice, physicians themselves can also record their consultations, point out two consultations and allow researchers or even colleagues or patients to review their consultations, as currently is being done in vocational training for physicians.

Whether feedback by telephone or face-to-face feedback is more useful in reflecting on the communication skills of physicians is not clear; both methods resulted in satisfactory evaluations from physicians. This suggests that especially the video-recorded consultations and the structured written report are the most valued characteristics of the feedback method. Several previous studies underline that feedback based on video-recorded consultations is an optimal method to reflect on and teach communication skills to physicians [7], [14] and [15]. Also, the online availability of the video-recorded consultations was valued positively. A previous study, focusing on pediatric visits that included a mental health concern, also found that the online demonstration of video-recorded communication skills is desirable [17].

Former studies have recommended regular feedback or training for practicing physicians [1], [2], [3] and [4]. As part of this continuing medical education, feedback on communication skills should also become a recurrent activity for experienced physicians. Continuing medical education should ideally include an experiential method, as for example our web-based video-feedback method, instead of formal didactic methods. Experiential methods have shown more effect on physicians’ performance than traditional continuing medical education [1], [2], [6] and [19].

\subsubsection{Relevance and application of the video-feedback method in health communication research}

A major strength of our feedback method is that physicians received feedback on different levels: (1) behavioral observations of physician-patient interaction and (2) patient-ratings of physician's communication skills. Besides, physicians evaluated their own communication skills. This is more or less in accordance with a recommendation from previous research [5], where the authors stated that measurements on communication skills should be performed on different levels, including the knowledge and attitude of physicians, their actual performance in daily practice and patient outcomes. Furthermore, Holm [4] suggests that continuing medical education must be based on both self assessment of physicians and peer review.

In concordance with the definition of 'strong feedback' of Van de Ridder and colleagues [12] our videofeedback method consists of well observable tasks and competencies, highly specific information, explicit standards, personal observation and is coded by expert observers and feedback providers. In contrast with their definition of strong feedback our method had not an explicit aim of performance improvement and we had no plan to re-observe. In addition, we did not provide feedback over a number of years as suggested by Veloski et al. [13], but only once in 2001 and once in 2008. 
The written individualized feedback report was seen as very useful by the physicians. Physicians could keep the report which enables them to look back at their performances and especially their improvements at any time. This feedback method can also be used to reflect on communication skills of medical students or other health care professionals. In addition, the video-recordings could be used to reflect on physicians' behavior with respect to medical content for example medical decisions on diagnoses.

We do not know whether our feedback method has a positive effect on physicians' performance, since we did not aim to measure the effects of our feedback sessions on physicians' actual communication skills. Future research could also examine if physicians improved their actual communication skills after the feedback, and possible differences between feedback by telephone compared to face-to-face feedback. Furthermore, further research could compare outcomes on physicians' communication between 2008 and 2001.

Besides, due to methodological limitations it was difficult to differentiate between the reactions of physicians on the feedback as a whole or to a specific detail of the feedback like the web-enabled link to the video-recorded consultation. More research with this feedback method is needed to estimate the impact of for example the web-enabled link or the written report.

In addition, we did not take context factors into account, like time pressure, previous and future contacts between physician and patient and goals and targets of both patient and physician [36]. These factors could have influenced the communication behavior of the physician, both positively and negatively.

Lastly, by using a secured web-link to the video-recorded consultations which was removed after the feedback session, we were able to take the privacy of the patient and physician into account.

\subsection{Conclusion}

This web-enabled video-feedback method is a feasible and appreciated tool to reflect on the communication skills of physicians. Physicians were especially satisfied with the web link to their recorded consultations and the structured written feedback report.

\subsection{Practice implications}

Continuing medical education requires a useful and structured method. This web-enabled video-feedback method is a valuable tool to provide feedback or training in communication skills to experienced physicians. It is based on both observations and patients' opinions about physicians' communication. Furthermore, our method consists of well observable tasks and competencies, highly specific information, explicit standards, personal observation and is coded by expert observers and feedback providers. This method could also be useful for medical students and other health care professionals.

\section{Conflict of interest}

The authors declare that they have no competing interests.

Role of funding

The research was funded by the Dutch Ministry of Health, Welfare and Sport. They had no role in the study design (collecting, analysis, interpretation of data), writing of the paper and the decision to submit this paper.

\section{Acknowledgements}

The authors thank the patients and physicians for their participation. We also thank Naima Abouri, Gwendolyn den Besten, Ramona de Groot, Anneloes Mulder and Audrey Ruane for coding the video recorded consultations and Evelien van Bijnen for her help in providing the feedback.

\section{REFERENCES}

[1] D.A. Davis, M.A. Thomson, A.D. Oxman and R.B. Haynes, Changing physician performance: a systematic review of the effect of continuing medical education strategies, J Amer Med Assoc 274 (1995), pp. 700-705.

[2] D.A. Davis, M.A. Thomson O'Brien, N Freemantle, F.M. Wolf, P. Mazmanian and A. Taylor-Vaisey, Impact of formal continuing medical education: do conferences, workshops, rounds, and other traditional continuing medical education activities change physician behavior or health care outcomes?, J Amer Med Assoc 282 (1999), pp. 867-874.

[3] R. Pérez-Cuevas, H. Reyes, Guiscafré, N. Juárez-Díaz, M. Oviedo, S. Flores and O. Muñoz, The primary care clinic as a setting for continuing medical education: program description, Can Med Assoc J 163 (2000), pp. 1295-1299. 
[4] H.A. Holm, Quality issues in continuing medical education, Brit Med J 316 (1998), pp. 621-624.

[5] R.L. Hulsman, W.J.G. Ros, J.A.M. Winnubst and J.M. Bensing, Teaching clinically experienced physicians communication skills a review of evaluation studies, Med Educ 33 (1999), pp. 55-58.

[6] K. Aspegren, BEME Guide no 2: teaching and learning communication skills in medicine - a review with quality grading of articles, Med Teach 21 (1999), pp. 563-570. [7] D.L. Roter, S. Larson, H. Shinitzky, R. Chernoff, J.R. Serwint, G. Adamo and L. Wissow, Use of an innovative video feedback technique to enhance communication skills training, Med Educ 38 (2004), pp. 145-147.

[8] N.K. Choudhry, R.H. Fletcher and S.B. Soumerai, Systematic review: the relationship between clinical experience and quality of health care, Ann Intern Med 142 (2005), pp. 260-263.

[9] A.W.M. Kramer, H. Dusman, L.H.C. Tan, J.J.M. Jansen, R.P.T.M. Grol and C.P.M. Vleuten et al., Acquisition of communication skills in postgraduate training for general practice, Med Educ 38 (2004), pp. 158-167.

[10] J.M. Bensing, F. Tromp, S. van Dulmen, A. van den Brink-Muinen, W. Verheul and F.G. Schellevis, Shifts in doctor-patient communication between 1986 and 2002: a study of videotaped general practice consultations with hypertension patients, BMC Fam Pract 7 (2006), pp. 1-7.

[11] M.J. Yedidia, C.C. Gillespie, E. Kachur, M.D. Schwarz, J. Ockene and A.E. Chepaitis et al., Effect of communication training on medical student performance, J Amer Med Assoc 290 (2003), pp. 1157-1165. [12] J.M. Van de Ridder, K.M. Stokking, W.C. McGaghie, O. ten Cate and J. Th, What is feedback in clinical education?, Med Educ 42 (2008), pp. 189-197.

[13] J. Veloski, J.R. Boex, M.J. Grasberger, A. Evans and D.B. Wolfson, Systematic review of the literature on assessment, feedback and physicians' clinical performance: BEME Guide No.7, Med Teach 28 (2006), pp. 117-118.

[14] N. Ozcakar, V. Mevsim, D. Guldal, T. Gunvar, E. Yildirim and Z. Sisli et al., Is the use of videotape recording superior to verbal feedback alone in the teaching of clinical skills?, BMC Public Health 9 (2009), pp. 1-5.

[15] S. Nilsen and A. Baerheim, Feedback on video recorded consultations in medical teaching: why students loathe and love it- a focus-group based qualitative study, BMC Med Educ 5 (2005), pp. 1-6.

[16] T. Coleman, Using video-recorded consultations for research in primary care: advantages and limitations, Fam Pract 17 (2000), pp. 422-427.

[17] K.J. Kemper, J.M. Foy, L. Wissow and S. Shore, Enhancing communication skills for pediatric visits through on-line training using video demonstrations, BMC Med Educ 8 (2008), pp. 1-8.

[18] D.J. Cegala and S. Lenzmeier Broz, Physician communication skills training: a review of theoretical backgrounds, objectives and skills, Med Educ 36 (2002), pp. 1004-1006.

[19] S. Hobma, P. Ram, A. Muijtjens, C. van der Vleuten and R. Grol, Effective improvement of doctorpatient communication: a randomised controlled trial, Br J Gen Pract (2006), pp. 580-586.

[20] W.A. Langewitz, P. Eich, A. Kiss and B. Wössmer, Improving communication skills - a randomized controlled behaviorally oriented intervention study for residents in internal medicine, Psychosom Med 60 (1998), pp. 268-276.

[21] R.C. Smith, J.S. Lyles, J. Mettler, B.E. Stoffelmayr, L.F. van Egeren and A.A. Marshall et al., The effectiveness of intensive training for residents in interviewing, Ann Intern Med 128 (1998), pp. 118-126.

[22] G. Makoul, Essential Elements of communication in medical encounters: The Kalamazoo consensus statement participants in the bayer-fetzer conference on physician-patient communication in medical education, Acad Med 76 (2001), pp. 390-393.

[23] T.S. Stein and J. Kwan, Thriving in a busy practice: physician-patient communication training, ACP: Eff Clin Pract (1999)

[24] M. Wensing, E. Vingerhoets and R. Grol, Feedback based on patient evaluations: a tool for quality improvement?, Patient Educ Couns 51 (2003), pp. 149-153.

[25] M. Wensing, R. Grol, C. van Weel and A. Felling, Quality assessment by using patients' evaluations of care, Eur J Gen Pract 4 (1998), pp. 150-153.

[26] E.S. Paxton, B.H. Hamilton, V.R. Boyd and B.L. Hall, Impact of isolated clinical performance feedback on clinical productivity of an academic surgery faculty, J Am Coll Surg 202 (2006), pp. 267-268.

[27] J. Noordman, P. Verhaak, I. van Beljouw and S. van Dulmen, Consulting room computers and their effect on general practitioner-patient communication: comparing two periods of computer use, Fam Pract 27 (2010), pp. 644-651.

[28] van denA. Brink-Muinen, A.M. van Dulmen, J.C.J.M. de Haes, Visser APh, F.G. Schellevis and J.M. Bensing, Has patients' involvement in the decision-making process changed over time?, Health Expect 9 (2006), pp. 333-342.

[29] van denA. Brink-Muinen, A.M. van Dulmen, H.P. Jung and J.M. Bensing, Do our talks with patients meet their expectations?, J Fam Pract 56 (2007), pp. 559-568. 
[30] R.A. Verheij, C.E. van Dijk, H. Abrahamse, R. Davids, H. van den Hoogen, J. Braspenning and T. van Althuis, Landelijk Informatienetwerk Huisartsenzorg. Feiten en cijfers over huisartsenzorg in Nederland, NIVEL/IQ, Utrecht/Nijmegen (2009) http://www.linh.nl (20-05-2010).

[31] D. Roter and S. Larson, The Roter interaction analysis system (RIAS): utility and flexibility for analysis of medical interactions, Patient Educ Couns 46 (2002), pp. 233-234.

[32] I.E.J. Milder, A. Blokstra, J. de Groot, S. van Dulmen and W.J.E. Bemelmans, Lifestyle counseling in hypertension-related visits - analysis of video-taped general practice visits, BMC Fam Pract 9 (2008), pp. $1-8$.

[33] J. Noordman, P. Verhaak and S. van Dulmen, Discussing patient's lifestyle choices in the consulting room: analysis of GP-patient consultations between 1975 and 2008, BMC Fam Pract 11 (2010), pp. 1-10.

[34] S.E. Stemler, A comparison of consensus, consistency, and measurement approaches to estimating interrater reliability, Pract Assess Res Eval 9 (2004)

[35] J. Sim and C.C. Wright, The Kappa statistic in reliability studies: use, interpretation, and sample size requirements, Phys Ther 85 (2005), pp. 257-258.

[36] J. Bensing, S. van Dulmen and K. Tates, Communication in context: new directions in communication research, Patient Educ Couns 50 (2003), pp. 27-32.

\section{[TABLES AND FIGURES]}

\section{Table 1}

Topics of the feedback report.

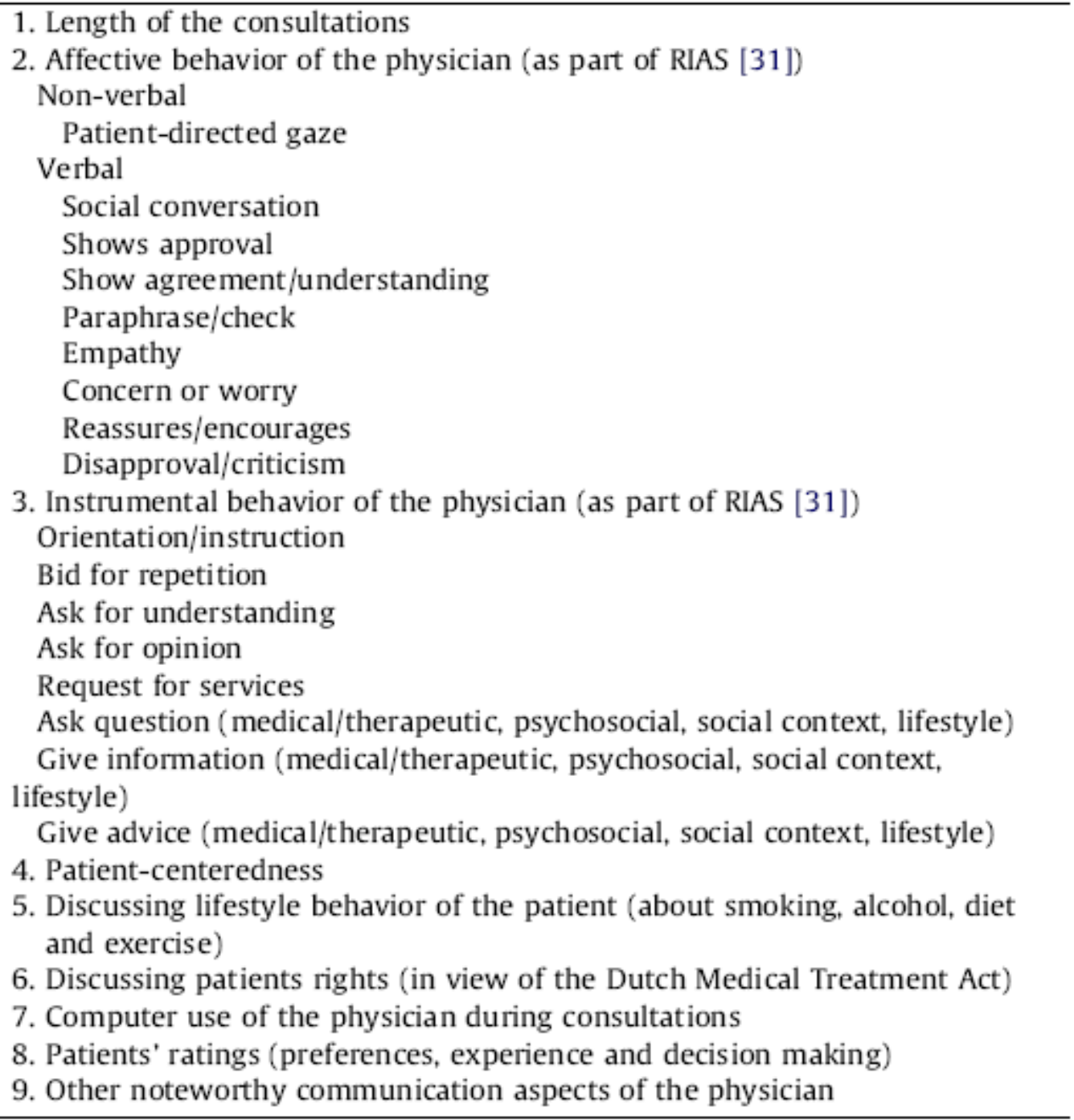




\section{Affective and instrumental behavior physician}

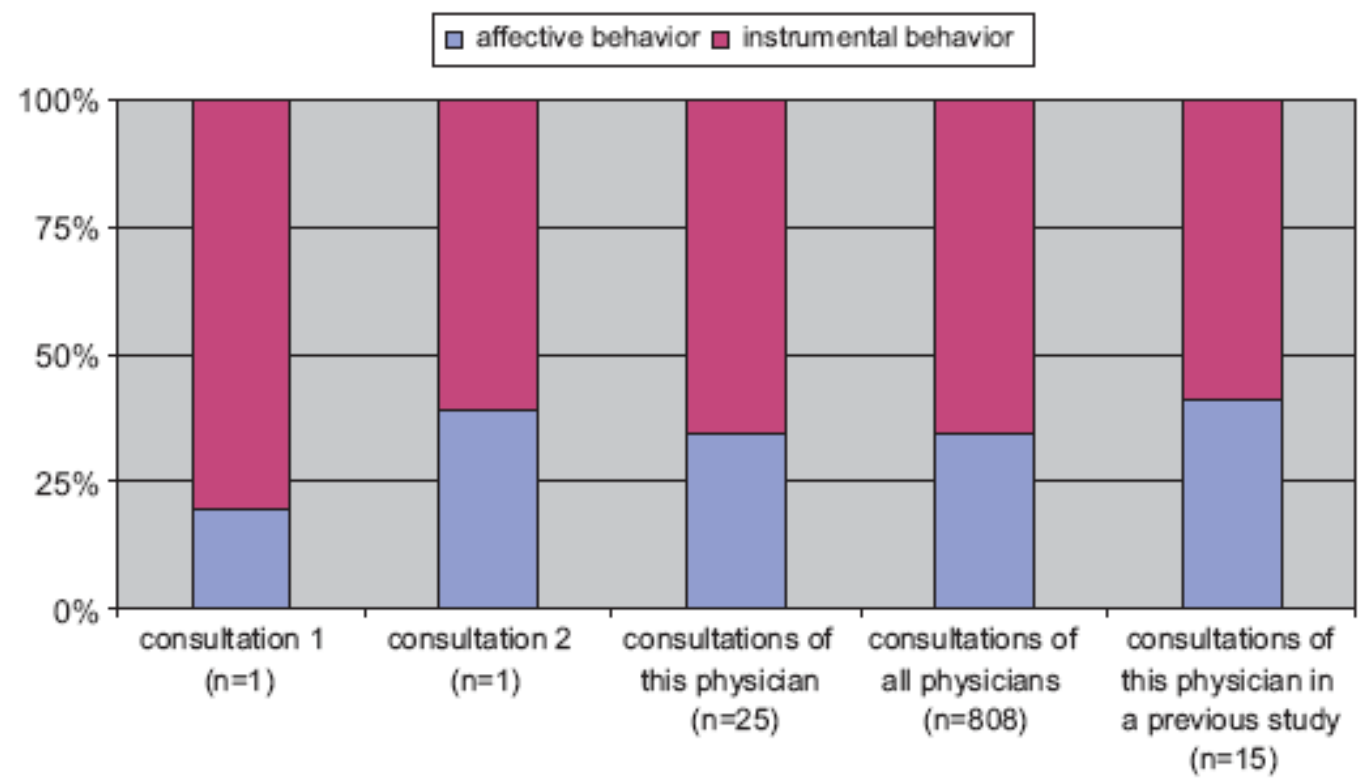

Fig. 1. Illustration of physician's affective and instrumental behavior, as described in the written report The physician in this example showed on average more instrumental than affective behavior. During consultation 1 of this physician the percentage affective behavior was low, but during consultation 2 it was higher. In a previous study this physician showed slightly more affective behavior than during the current study. An example of a whole written feedback report can be obtained by contacting the corresponding author.

Table 2

Questions asked to physicians before and after the feedback.

Questions before the feedback

1. What is your opinion about your communication with the patient during the two selected consultations? Please point out positive and improvement points for the two consultations.

2. What do you find difficult about communicating with a patient in general?

After the feedback

3. What is your opinion on the feedback you received? Do you miss something?

4. What is your opinion about the method of feedback you received? (by telephone or face-to-face, written report and able to watch your consultations trough a webenabled link)

5. You also received face-to-face feedback during a previous study in 2001. Can you compare the method of feedback from 2001 with the one you just received? Which one do you prefer and why? 
Table 3

Interrater reliability, Pearson's correlation \& Cohen's Kappa.

\begin{tabular}{|c|c|}
\hline & $\begin{array}{l}\text { Pearson's } \\
\text { correla- } \\
\text { tion }^{\mathrm{a}}\end{array}$ \\
\hline RIAS coding & 20012008 \\
\hline Patient-directed gaze & 0.80 \\
\hline Questions asked by physicians & 0.900 .80 \\
\hline Information given by physicians & 0.900 .79 \\
\hline Physicians' empathy & 0.51 \\
\hline Paraphrase/ check & 0.850 .77 \\
\hline Structuring & 0.870 .58 \\
\hline Show approval & 0.950 .93 \\
\hline Other observed topics & $\begin{array}{l}\text { Cohen's } \\
\text { Kappa }^{\text {b }}\end{array}$ \\
\hline Patient-centeredness & $-\quad 0.79$ \\
\hline Discussing smoking behavior & 0.79 \\
\hline Discussing alcohol use & 0.66 \\
\hline Discussing nutrition & 0.73 \\
\hline Discussing physical activity & 0.74 \\
\hline $\begin{array}{l}\text { Discussing patient rights (in view of the } \\
\text { Dutch Medical Treatment Act) }\end{array}$ & 0.80 \\
\hline No computer use & 1.00 \\
\hline $\begin{array}{l}\text { Computer use: to search for or read } \\
\text { something }\end{array}$ & 0.80 \\
\hline $\begin{array}{l}\text { Computer use: to prescribe or refer } \\
\text { a patient }\end{array}$ & 0.95 \\
\hline $\begin{array}{l}\text { Computer use: while the patient is changing clothes (for physical } \\
\text { examination) }\end{array}$ & 0.93 \\
\hline $\begin{array}{l}\text { Computer use: when the physician is } \\
\text { talking }\end{array}$ & 0.61 \\
\hline Computer use: when the patient is talking & 0.75 \\
\hline $\begin{array}{l}\text { Computer use: while the patient } \\
\text { waits silently }\end{array}$ & 0.93 \\
\hline \multicolumn{2}{|c|}{$\begin{array}{l}\text { a Pearson's correlation interpretation: below } 0.30 \text { : poor, } 0.31-0.50 \text { : slight/fair, } \\
0.51-0.80 \text { : moderate/substantial, } 0.81-1.00 \text { : almost perfect. When utterances were } \\
\text { coded less than } 5 \% \text { we did not calculate the interrater reliability. } \\
\text { b Cohen's Kappa interpretation: below } 0.00 \text { : poor, } 0.00-0.21 \text { : slight, } 0.21-0.40 \text { : } \\
\text { fair, } 0.41-0.60 \text { : moderate, } 0.61-0.80 \text { : substantial, } 0.81-1.00 \text { : almost perfect. In } \\
2001 \text { the interrater reliability was not calculated for other topics than part of the } \\
\text { RIAS coding. }\end{array}$} \\
\hline
\end{tabular}

